\title{
Palmar Fibromatosis: an Analysis of 25 Cases
}

\author{
(D) Mehmet Sabri Balık¹, (D) Recep Bedir²
}

${ }^{1}$ Recep Tayyip Erdoğan University Faculty of Medicine, Department of Orthopedics and Traumatology, Rize, Turkey

${ }^{2}$ Recep Tayyip Erdoğan University Faculty of Medicine, Department of Medical Pathology, Rize, Turkey

\section{Abstract}

Objective: Dupuytren's contracture (DC) is a benign tumor that results in nodular or fibrous band-like thickening of the palmar fascia and leads to palmar and digital contractures. Although they are benign lesions, post-operative recurrence is frequent. In the present study, we retrospectively analyzed clinicopathological findings of 25 cases that underwent surgery for DC. We also aimed to determine the relationship between relapse and Ki-67 proliferation index and smooth muscle actin (SMA) staining intensity in excision materials by immunohistochemical method.

Methods: The demographic characteristics, severity of contracture, treatment type, Ki-67 proliferation index, SMA staining intensity and recurrence were evaluated retrospectively in 25 patients who were operated with the diagnosis of DC at the Department of Orthopedics and Traumatology in Recep Tayyip Erdogan University between 2009 and 2015.

Results: The age range of the patients was $42-75$ years (mean age: 55 years), and 6 were female and 19 were male. Fifteen of the lesions were in the right hand, and 10 were in the left hand. All patients underwent extensive palmar fascia excision with regional intravenous anesthesia. Only one patient had recurrence. Ki-67 proliferation index was 1-2\% in patients without recurrence, however, $>5 \%$ nuclear positivity was detected in a patient with recurrence. In addition, strong positive staining for SMA was observed in this patient.

Conclusion: The use of Ki-67 proliferation index and SMA staining intensity to evaluate fibroblastic proliferation in the pathological examination of surgical DC specimens may be valuable in clinical follow-up in terms of recurrence.

Keywords: Dupuytren's contracture, Dupuytren's disease, fasciectomy, palmar contracture

\section{INTRODUCTION}

Dupuytren's contracture (DC) was first reported in 1777 by Henry Cline. It was described in detail by Baron Guillaume Dupuytren, a French surgeon, in $1834(1,2)$. DC is a tumor that results in nodular or fibrous band-like thickening of the palmar fascia in the palm and fingers. They are benign in character; however, they may also be locally aggressive. The clinical symptoms are seen in the palms and fingers. It is generally seen as a movement restriction and a painless mass $(3,4)$. DC can be associated with other fibromatoses including plantar fibromatosis (Ledderhose disease), penile fibromatosis (Peyronie disease), and fibromatosis of the dorsum of the proximal interphalangeal joints (Garrod's nodules or knuckle pads) (5). The etiology is not clear. It extends from the palm towards the fingers in the form of myofibroblastinduced fibrous bands. Over time, palmar and digital flexion contractures occur. It disrupts hand function and affects quality of life (6). Even though it is widely seen among ethnic groups, its prevalence is high in North American men. Moreover, its prevalence increases with age (4). Despite recent research on different treatments (7), the surgical method commonly used in the treatment of contracture is incision and fasciectomy (8, $9)$. Post-operative recurrence has been reported to vary in a wide range from 0 and $70 \%$ (10). Despite different treatment modalities, the likelihood of recurrence is quite high (7). In the literature, there are studies investigating the relationship

E-posta: sabribalik@yahoo.com ORCID ID: orcid.org/0000-0001-9729-3927

Cite this article as: Balık M.S, Bedir R, Palmar Fibromatosis: An Analysis of 25 Cases. Eur Arch Med Res 2019; 35 (1):43-48.

${ }^{\circ}$ Copyright 2019 by the Health Sciences University, Okmeydanı Training and Research Hospital

European Archives of Medical Research published by Galenos Publishing House. 
between the surgical method and the clinic in terms of determining the recurrence of $D C(10,11,12)$. For this reason, it is very important to estimate in which cases the recurrence will be observed.

In the present study, it was aimed to investigate the relationship between recurrence and Ki-67 proliferation index, smooth muscle actin (SMA) staining intensity, and clinicopathological findings of cases who had been diagnosed with DC and undergone surgical intervention.

\section{METHODS}

After the approval of Recep Tayyip Erdoğan University Ethics Committee (no: 34, date: 12.23.2016), the clinical and pathological records of 25 cases diagnosed with DC in the Department of Pathology between 2009 and 2015 were documented. Written informed consent was obtained from the patients. The hematoxylin-eosin (HE) stained sections were retrospectively analyzed. Age, gender, localization, contracture level, treatment type, and recurrence were determined. In addition, Ki-67 proliferation index and SMA staining intensity were examined.

HE-stained preparations were fixed in formol. The $5 \mu \mathrm{m}$-thick cross-sections obtained from the selected paraffin blocks were taken on slides treated with HistoGrip ${ }^{\mathrm{TM}}$ (Zymed Laboratories, CA, USA). After deparaffinization, the cross-sections were boiled in citrate buffer $(\mathrm{pH}=6)$ in order to extract antigen. In immunohistochemical examination using the streptavidinbiotin method, Ki-67 (MM1, Cod: 801704, pre-prepared) primary antibody and SMA (MM1, Cod: 28330030, pre-prepared) were used, as well as aminoethyl carbazole chromogen used as chromogen. Mayer's hematoxylin was used in contrast staining. Mounting medium (Zymed) was used when closing the slide. Sections were analyzed by Olympus BX50 light microscope (Olympus America, Inc., NY, USA).

Randomly selected tumor sites were examined in Ki-67 scoring. The ratio of the number of positive stained cells to the total number of cells under 5 different magnification zones (40X) for each sample was determined as the labeling index (L1). Only the nuclei that were stained clearly were accepted as positive. The number of mitosis was determined at 10X magnification in a randomly selected microscopic region (x400). SMA staining intensity was divided into 3 groups as mild $(+)$, moderate $(++)$, and intense $(+++)$.

\section{Statistical Analysis}

The SPSS 16.0 statistical software package (SPSS Inc, Chicago, Illinois, USA) was used for all calculations. Normality was tested using the Kolmogorov-Smirnov test. Data are presented as median (inter-quartile range, IQR) for non-normally distributed continuous variables. Measurement of central tendency was given as a box-plot graphic. Difference between variables were evaluated by Kruskal-Wallis with post hoc Mann-Whitney U test. Group differences with $p$ value $<0.05$ were accepted significant.

\section{RESULTS}

Twenty-five DC cases were examined. The patients' ages ranged from 42 and 75 years, with a mean age of 55 years. Twentyfour percent of the patients were female and $76 \%$ were male. All patients underwent extensive palmar fascia excision under regional intravenous anesthesia. The excised masses were in the form of cords. Fifteen cases (60\%) were in the right hand and $10(40 \%)$ were in the left hand. The most frequently observed contracture localization was the $4^{\text {th }}$ and $5^{\text {th }}$ fingers. Seven patients had type-II diabetes mellitus (DM) for more than five years. Table 1 shows the distribution of DC cases by age, gender, type of treatment, localization, Ki-67 proliferation index, and

\begin{tabular}{|c|c|c|c|c|c|c|}
\hline Case no & Age & Gender & Recurrence & Side & Ki-67 & SMA \\
\hline 1 & 49 & Female & No & Right & $0 \%$ & + \\
\hline 2 & 56 & Male & No & Right & $1 \%$ & + \\
\hline 3 & 42 & Male & No & Left & $1 \%$ & + \\
\hline 4 & 75 & Female & No & Right & $0 \%$ & + \\
\hline 5 & 42 & Male & No & Left & $1 \%$ & + \\
\hline 6 & 56 & Male & No & Right & $2 \%$ & ++ \\
\hline 7 & 62 & Male & Yes & Right & $5 \%$ & +++ \\
\hline 8 & 54 & Male & No & Left & $1 \%$ & + \\
\hline 9 & 46 & Male & No & Right & $2 \%$ & + \\
\hline 10 & 46 & Male & No & Right & $1 \%$ & + \\
\hline 11 & 67 & Male & No & Left & $2 \%$ & + \\
\hline 12 & 75 & Male & No & Left & $2 \%$ & ++ \\
\hline 13 & 63 & Male & No & Left & $1 \%$ & + \\
\hline 14 & 49 & Male & No & Right & $1 \%$ & + \\
\hline 15 & 67 & Male & No & Right & $1 \%$ & + \\
\hline 16 & 75 & Male & No & Right & $1 \%$ & + \\
\hline 17 & 50 & Female & No & Left & $2 \%$ & + \\
\hline 18 & 60 & Male & No & Left & $1 \%$ & + \\
\hline 19 & 50 & Male & No & Right & $1 \%$ & + \\
\hline 20 & 58 & Male & No & Right & $1 \%$ & + \\
\hline 21 & 57 & Female & No & Right & $1 \%$ & + \\
\hline 22 & 45 & Male & No & Right & $2 \%$ & ++ \\
\hline 23 & 54 & Male & No & Left & $1 \%$ & + \\
\hline 24 & 52 & Female & No & Left & $2 \%$ & + \\
\hline 25 & 45 & Female & No & Right & $1 \%$ & + \\
\hline
\end{tabular}


SMA staining intensity. The treatment was extensive excision for all contractures, and recurrence was observed only in one patient after approximately one year. All the patients admitted with a painless mass growing slowly on the hand and contracture of the fingers and metacarpophalangeal joint. Bone tissue was normal in the conventional radiological examination of the patients. Mass shadow was observed in soft tissues. In six cases with digital contracture, the clinical problem was trigger finger due to the compression in the A1 pulley. Nodules accompanied fibrous bands in 12 cases. On physical examination of all cases, there was a fibrous band that caused $20-30^{\circ}$ flexion contracture in the metacarpophalangeal joint in the hand.

Pathological examination revealed irregularly shaped tissues with localized elastic nodules of different sizes and graywhite color. Microscopic examination revealed fibroblastic proliferation in fascial tissue samples (Figure 1). There was a severe increase in cellularity in four cases, moderate increase in eight cases, mild increase in seven cases, and no increase in six cases. In immunohistochemical analysis, Ki-67 proliferation rates of lesions were generally low (1-2\%), but high in only one case (5\%) (Figures 2 and 3). SMA staining was intense in one case (4\%), moderate in three cases (12\%), and mild in 21 cases (84\%) (Figure 4). The relationship between Ki-67 proliferation rates and age and gender is presented in Figure 5.

\section{DISCUSSION}

Although the etiology of DC is not clear, it has been reported to be associated with age, genetic factors, gender, alcohol and smoking, as well as working $(3,4,5,9,13)$. The most common site of the disease is palmar fascia. But, the involvement of body parts other than the palm can also be seen (5). Furthermore, it has

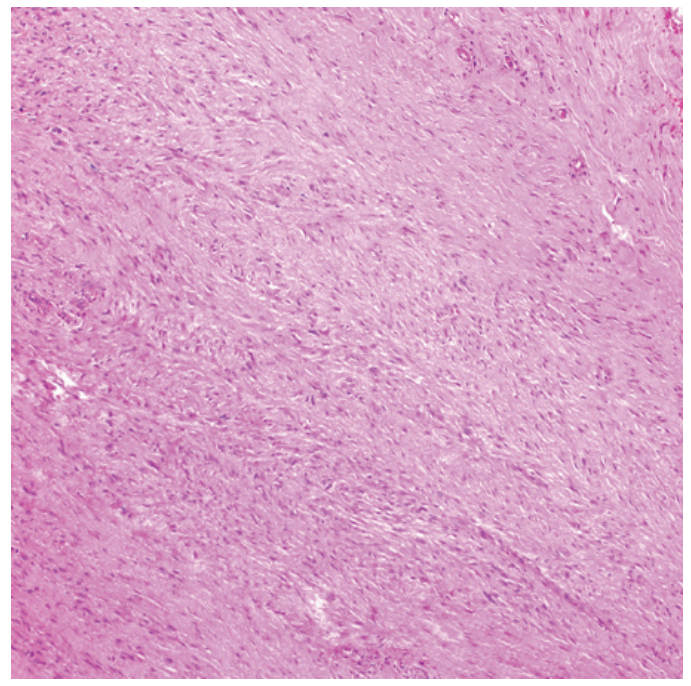

Figure 1. Lesion with proliferation of fibroblasts (H\&Ex100) been reported to be associated with frozen shoulder syndrome due to its fibro-proliferative characteristics (11). However, no involvement was observed in other body regions in our cases.

In terms of gender, the prevalence of DC was 1.5-fold higher in males (14). It is more common especially among 40 year-old males (15). Palmar fascia is the target tissue for androgen activity. The higher number of androgen receptors in DC when compared to normal palmar fascia explains the higher frequency in male gender (16). In our patient group, the dominant gender was male with $76 \%$. However, female/male ratio was higher than the literature. Moreover, the males had more severe contractures than females.

DC is a hand pathology that is frequently observed with DM. Its prevalence varies between $16 \%$ and $42 \%$ (17). The prevalence of DC increases with the duration of DM (18). The formation of contracture at hand is associated with smoking and free radical

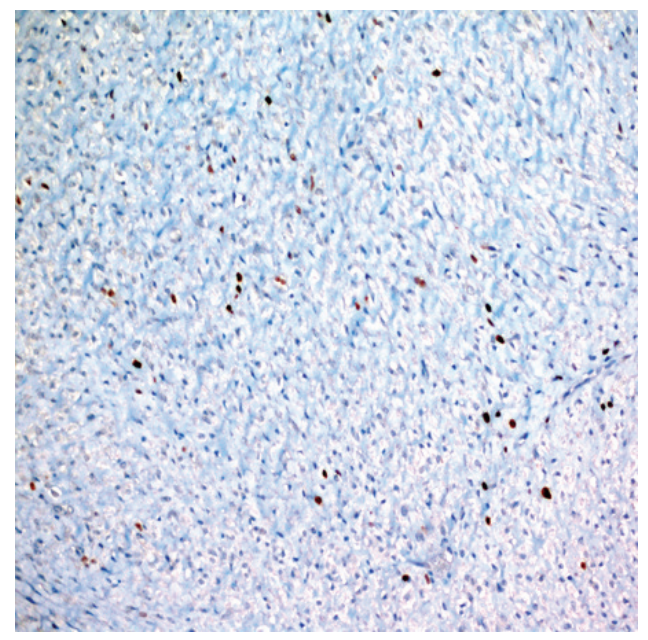

Figure 2. Low Ki-67 proliferation index (x200)

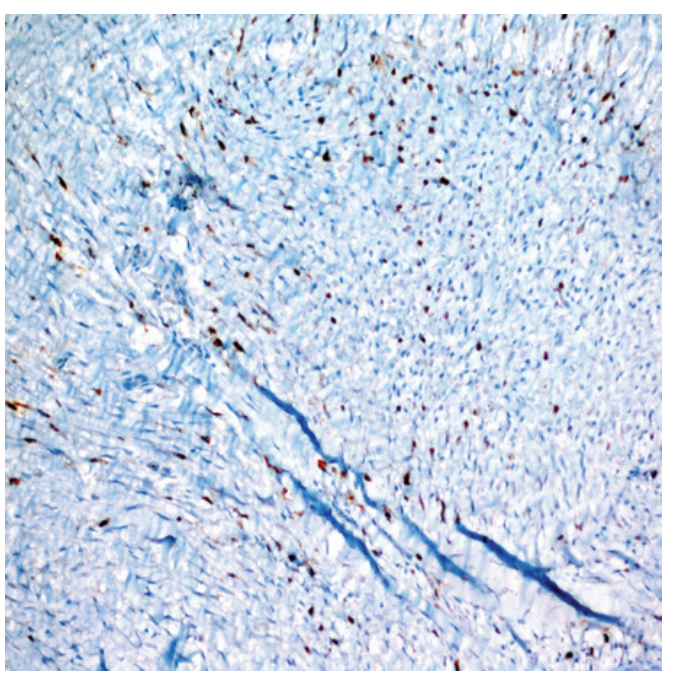

Figure 3. High Ki-67 proliferation index (x200) 


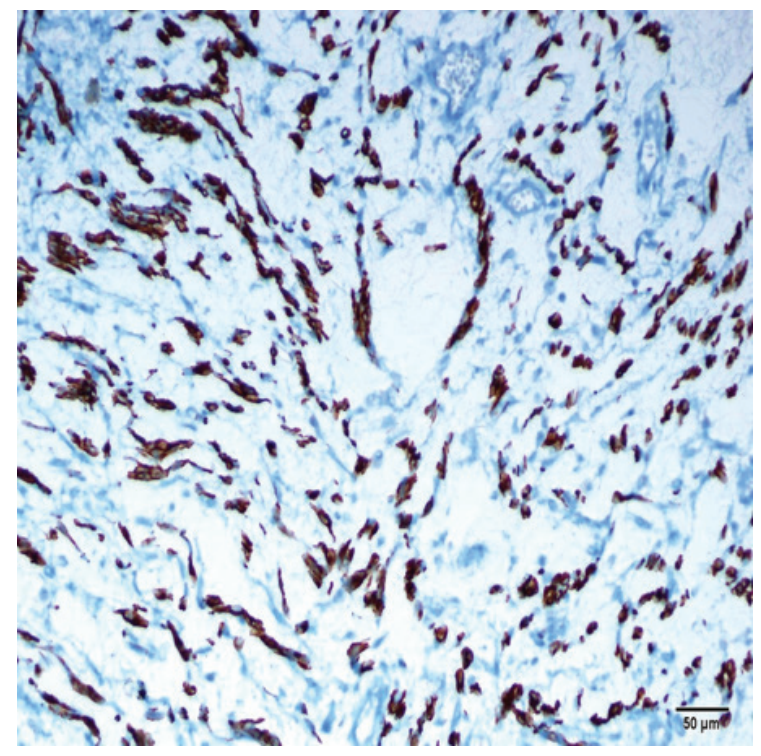

Figure 4. Strong smooth muscle actin positivity (x200)

(in DM) and local ischemia (13). Twenty-eight percent of our cases had DM. The prevalence was consistent with the literature. However, in all cases, there were nodules accompanying the fibrous bands. But, there was no difference between the duration of DM and DC clinic.

In the histopathology of DC, there are proliferative, involutional, and residual phases. In the proliferative phase, the number of fibroblasts increases. Due to various factors, fibroblasts form myofibroblasts. The myofibroblasts show the characteristics of both smooth muscle cell and fibroblasts. Thus, they have the ability to contract (19). The involutional phase is characterized by cell loss and the number of myofibroblasts decreases (20). In residual phase, reductions are observed in the number of myofibroblasts. Together with mature fibroblasts, also the amount of collagen increases. At this phase, type III collagen increases $(21,22)$. Moreover, nodules form band-like structure from the mature scar tissue (23). Myofibroblasts play significant role in tissue contraction in DC (24).

DC nodules have a cell density of myofibroblasts that provides fibroblast and smooth muscle cell character. Compared with the cells derived from band, positive SMA staining was found to be higher in majority of nodule cell culture and it corroborates this conclusion (25).

Various factors have been proposed to play role in post-operative clinical recurrence $(26,27)$. One of these factors is the relationship between myofibroblasts and intracellular microtubules. The presence of myofibroblast in residual tissue can be used to predict the likelihood of recurrence. For this reason, radical excision of the palmar fascia and the involved skin zone with

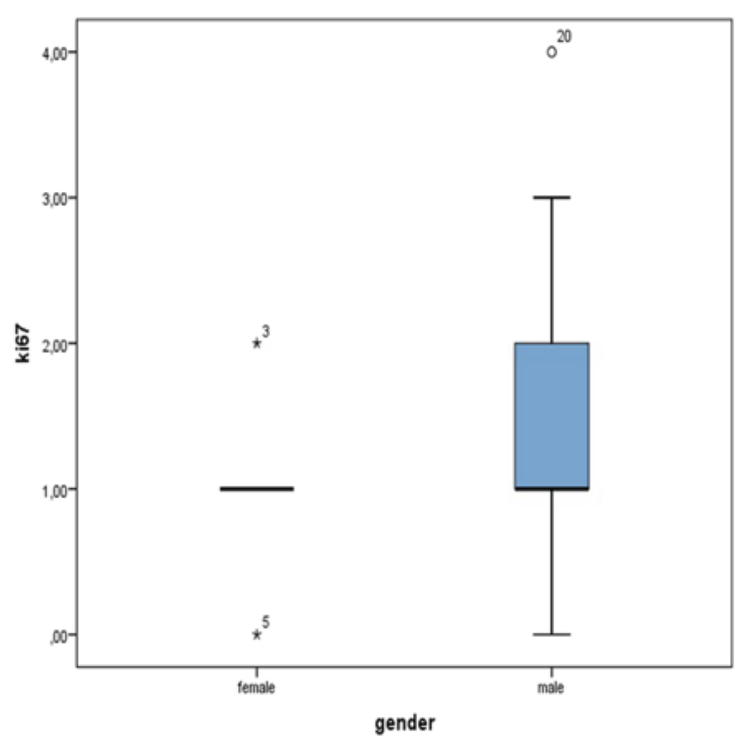

Figure 5. a) Relationship between Ki-67 proliferation rates and gender

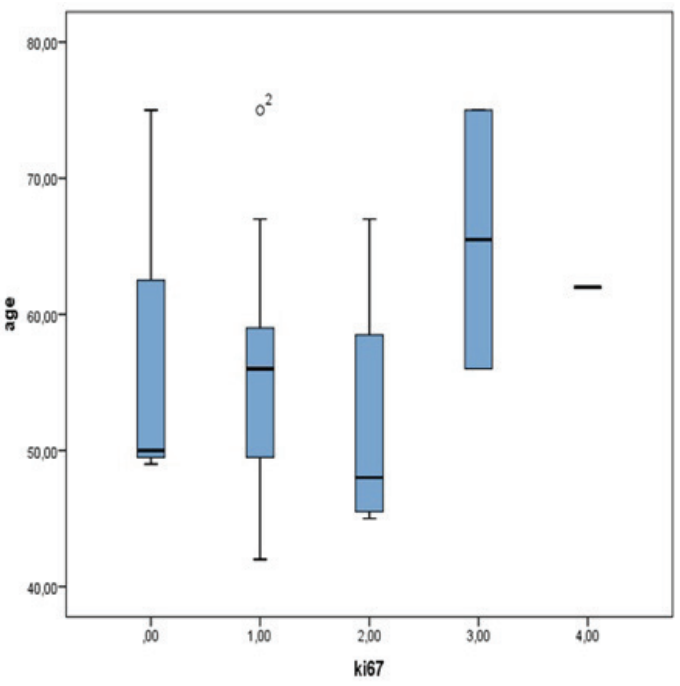

Figure 5. b) Relationship between Ki-67 proliferation rates and gender open surgery method and covering the surgery zone with fullthickness skin graft is useful in preventing the contracture (26).

Passive fibrous band fibroblasts may be reactivated as myofibroblasts with the effect of growth factors. This may be a major factor for high post-operative recurrence rates or for progression after injury (27).

Increased post-operative recurrence increased the importance of predicting the recurrence. Recurrence and aggressiveness can be estimated using a high level of increase in cellularity in DC, because the cellularity tends to decrease and the amount of type-III collagen tends to increase as the disease matures. Myofibroblasts decrease and the fibroblasts replace them in the residual phase (28). Significant increase in cellularity was 
observed in four of our cases, but the recurrence was seen in only one of these cases.

If DC is aggressive and the proliferative phase is stronger, maturation is delayed. Recurrence of this disease is known to be associated with cellular diversity. The collagen rate is lower in aggressive cases (28). The presence of SMA in myofibroblasts is an indicator of disease activity. It is commonly found in aggressive surgical materials (29). Ki-67 proliferation index, which is a proliferative marker, can be frequently seen at high levels in aggressive cases (28). When our symptomatic cases were operated for $20-30^{\circ}$ flexion contracture in the metacarpophalangeal joint, moderate-strong SMA positive staining was observed in three of four cases with high cellularity, and Ki-67 proliferation index was found to be at high level only in one case. The level of Ki-67 proliferation index was low in other cases. Despite the absence of benign lesions, the post-operative recurrence is common. Extensive surgical excision is very important because of the insufficient surgical excision (24). However, the recurrence was observed in our case with $>5 \% \mathrm{Ki}-67$ proliferation index. Because of the recurrence despite the extensive excision of the palmar fascia, the use of Ki-67 proliferation index and SMA staining intensity in the analysis of the fibroblastic proliferation in the pathological examination of excised materials in DC may be beneficial in the clinical follow-up of the recurrence of the lesion.

The main limitation of the present study is limited number of cases. Moreover, no histopathological comparison could be made between different surgical samples, such as nodules and bands. However, despite all the limitations, we believe that it will contribute to further studies on recurrence in DC.

\section{CONCLUSION}

We believe that the use of Ki-67 proliferation index and SMA staining intensity with immunohistochemical staining method in surgical specimens in order to determine the clinical course of DC might be beneficial in estimating the recurrence.

\section{Ethics}

Ethics Committee Approval: Ethics committee approval was received for this study from the ethics committee of Recep Tayyip Erdoğan University Ethics Committee (no: 34, date: 12.23.2016)

Informed Consent: Written informed consent was obtained from the patients.

Peer-review: External and internal peer-reviewed.

\section{Authorship Contributions}

Surgical and Medical Practices: M.S.B., R.B., Concept: M.S.B., R.B., Design: M.S.B., R.B Data Collection or Processing: M.S.B., R.B., Analysis or Interpretation: M.S.B., R.B., Literature Search: M.S.B., Writing: M.B.S.

Conflict of Interest: No conflict of interest was declared by the authors.

Financial Disclosure: The authors declared that this study received no financial support.

\section{REFERENCES}

1. Dupuytren BG. Permanent retraction of the fingers, produced by an affection of the palmar fascia. Lancet 1834;2:222-5.

2. Townley WA, Baker R, Sheppard N, Grobbelaar AO. Dupuytren's contracture unfolded. BMJ 2006;332:397-400.

3. Stahl S, Calif E. Dupuytren's palmar contracture in women. Isr Med Assoc J 2008;10:445-7.

4. Weinstein AL, Haddock NT, Sharma S.Dupuytren's disease in the Hispanic population: a 10-year retrospective review. Plast Reconstr Surg 2011;128:1251-6.

5. Hu FZ, Nystrom A, Ahmed A, Palmquist M, Dopico R, Mossberg I, et al. Mapping of an auto-somal dominant gene for Dupuytren's contracture to chro-mosome $16 q$ in a Swedish family. Clin Genet 2005;68:424-9.

6. Dibenedetti DB, Nguyen D, Zografos L, Ziemiecki R, Zhou X. Prevalence, incidence and treatments of Dupuytren's disease in the United States: results from a population-based study. Hand 2011;6:149-58.

7. Ahn HC, Cheon HJ, Kim KC, Woo SH. Dupuytren's contracture felease with straight line incision and multiple Z-plasty. J Korean Soc Surg Hand 2011;16:35-41.

8. Descatha A, Carton M, Mediouni Z, Dumontier C, Roquelaure Y, Goldberg $\mathrm{M}$, et al. Association among work exposure, alcohol intake, smoking and Dupuytren's disease in a large cohort study. BMJ Open 2014;4:e004214.

9. Hurst L. Dupuytren's contracture. In: Green D, Hotchkiss R, Pederson WC, editors. Operative hand surgery. 5th ed. New York: Churchill Livingstone; 2005. pp. $159-185$

10. Godtfredsen NS, Lucht H, Prescott E, Sorensen TI, Gronbaek M. A prospective study linked both alcohol and tobacco to Dupuytren's disease. J Clin Epidemiol 2004;57:858-63.

11. Degreef I, Steeno P, De Smet L. A survey of clinical manifestations and risk factors in women with Dupuytren's disease. Acta Orthop Belg 2008;74:45660

12. Degreef I, De Smet L. A high prevalence of Dupuytren's disease in Flanders. Acta Orthop Belg 2010;76:316-20.

13. Trojian TH, Chu SM. Dupuytren's disease: diagnosis and treatment. Am Fam Physician 2007;76:86-9.

14. Pagnotta A, Specchia N, Greco F. Androgen receptors in Dupuytren's contracture. J Orthop Res 2002;20:163-8.

15. Loos B, Puschkin V, Horch RE. 50 years experience with Dupuytren's contracture in the Erlangen University hospital: A retrospective analysis of 2919 operated hands from 1956 to 2006. BMC Musculoskelet Disord 2007;8:60 
16. Pandey A, Usman K, Reddy H, Gutch M, Jain N, Qidwai S. Prevalence of hand disorders in type 2 diabetes mellitus and its correlation with microvascular complications.Ann Med Health Sci Res 2013;3:349-54.

17. Magro G, Lanteri E, Micali G, Paravizzini G, Travali S, Lanzafame S. Myofibroblasts of palmar fibromatosis co-express transforming growth factor-alpha and epidermal growth factor receptor. J Pathol 1997;181:213-7.

18. Wilutzky B, Berndt A, Katenkamp D, Koshmehl H. Programmed cell death in nodular palmar fibromatosis (Morbus Dupuytren). Histol Histopathol 1998; 13:67-72.

19. Melling M, Karimian-Teherani D, Mostler S, Behnam M, Sobal G, Menzel EJ. Changes of biochemical properties in Dupuytren disease. Arch Pathol lab Med 2000;124:1275-81.

20. Bricley-Parsons D, Glimcher MJ, Smith RJ, Albin R, Adams JP. Biochemical changes in the collagen of the palmar fascia in patients with Dupuytren's disease. J Bone Joint Surg 1981;63:787-97.

21. Hamamoto H, Ueba $Y$, Sudo $Y$, Sanada H, Yamamuro T, Takeda T. Dupuytren's contracture: morphological and biochemical changes in palmar aponeurosis. Hand 1982;14:237-47.

22. Tomasek JJ, Vaughan MB, Haaksma CJ. Cellular structure and biology of Dupuytren's disease. Hand Clin 1999;15:21-34.
23. Dave SA, Banducci DR, Graham WP 3rd, Allison GM, Ehrlich HP. Differences in alpha smooth muscle actin expression between fibroblasts derived from Dupuytren's nodules or cords. Exp Mol Pathol 2001;71:147-55.

24. Rudolph R, Vande Berg J. The myofibroblast in Dupuytren's contracture. Hand Clin 1991;7:683-92

25. Bisson MA, McGrouther DA, Mudera V, Grobbelaar AO. The different characteristics of Dupuytren's disease fibroblasts derived from either nodule or cord: expression of alpha-smooth muscle actin and the response to stimulation by TGF-beta1. J Hand Surg Br 2003;28:351-6.

26. Forsman M, Kallioinen L, Kallioinen M, Ryhanen J.Dupuytren's contracture; increased cellularity proliferation, is there equality? Scand J Surg 2005;94:715.

27. Andrew JG, Andrew SM, Ash A, Turner B. An investigation into the role of inflammatory cells in Dupuytren's disease. J Hand Surg 1991;16:267-71.

28. Roush TF, Stern PJ. results following surgery for recurrent Dupuytren's disease. J Hand Surg 2000;25-A:291-6.

29. Degreef I, de Smet L. Risk factors in Dupuytren's diathesis: is recurrence after surgery predictable? Acta Orthop Belg 2011;77:27-32. 